\title{
The Effect of Metaphorical Competence on Students' Writing Skills
}

\author{
Yi Zhang \\ Tianjin Polytechnic University, Tianjin, China \\ Email: yizhang@163.com
}

How to cite this paper: Zhang, Y. (2019). The Effect of Metaphorical Competence on Students' Writing Skills. Creative Education, 10, 151-155.

https://doi.org/10.4236/ce.2019.101011

Received: December 17, 2018

Accepted: January 20, 2019

Published: January 23, 2019

Copyright (C 2019 by author(s) and Scientific Research Publishing Inc. This work is licensed under the Creative Commons Attribution International License (CC BY 4.0).

http://creativecommons.org/licenses/by/4.0/

\begin{abstract}
The article is about to indicate that metaphorical competence (MC) can be acquired in classroom instruction, and plays the constructive role in students' linguistic competence and their writing skills. Subjects were chosen and divided into the experimental group (EG) and the control group (CG). Subjects from EG were instructed with metaphorical theory and relative writing practice, while the other were taught with traditional ways. Their writings were tested in terms of lexical density, metaphorical expressions and linguistic errors. Data and results show that the former performs better in increasing lexical density and metaphorical expressions, and eliminating the linguistic errors.
\end{abstract}

\section{Keywords}

Writing, Second Language Acquisition, Metaphor Awareness, Metaphorical Competence (MC)

\section{Introduction}

College English Curriculum Requirements makes it critical point that writing is the vulnerable skill for the language learners. Raimes claimed that writing was of vital importance for the foreign language learners to develop their abilities (Raimes, 1983: p. 142). And Dvorak (1986) stated that the improvement on the ability to produce appropriate communicative written-discourse was directed towards the enhancement of linguistic and communicative competence.

In practice, students are expected to elaborate logically and clearly their main idea and purpose when organizing their texts. They produce expressions, however, structurally correct but semantically anomalous and loosely organized. They focus hardly on their thesis statement, nor list their many ideas with enough supporting facts and evidence. Following paragraphs are excerpted from 
our students' writing assignments.

${ }^{*}$ Courses in our school is like lunch or supper, while training course is like extra food we eat at our spare time. Main food is of great importance to sustain our life, so school course is the most important for our study. But training course can meet the needs when we are in shortage.

* Some insist in on intensive training can improve the ability of study and give you a good score. The teacher can teach you something you can't learn in school. However, some can't agree that. They said the function intensive training course given to you is not as same as we expect. Many intensive training course even cheap the students.

From their essay, we cannot understand what lunch or supper is to Courses, and extra food to training course. The following sentence "Main food is of great importance ... for our study" provides little clarification to the relationship of lunch, supper, and extra food to course and training. Additionally, the transitional word "But" is not suitable to connect the two sentences because there is not adversative relation between them. According to Danesi (1986), those anomalous writings are resulted from students' lack of conceptual fluency.

According to the survey among our students, most agreed that writing was the tough task, and admitted that words and rules of English were learned in isolation, which contributes to their difficulties in searching for proper words to suit the context to achieve the fluency and appropriateness in their writing.

To cope with the mentioned problems in writing, Linda Flower and Johen R. Hayes put forward, in 1981, the cognitive process of writing as follows, and discovered that writing was made up of various cyclic sub-processes (Figure 1).

Including three elements of task environment, writer's long-term memory, and writing process, the cognitive process was also called process-oriented approach. Flower and Hayes suggested that it focused on learner-centered. It meant that teachers instructed students how to set goals, how to solve problems, and how to represent meaning.

The cognitive process could make a difference in students' writing on the assumption that students had the same intellectual resources and the cognitive process. But variations in individual, language proficiency, and level of cognitive development must be reckoned with in writing process. Christian Knoeller (2009) encouraged students to use the cognitive tool to figure out their own writing processes, and improve language proficiency (Ortony, 1993). Recently, enlightened by theories of conceptual metaphor, many researchers, home and abroad, have proposed the approach of applying the cognitive metaphor in writing. According to Ricoeur (1978), conceptual metaphor could be used as heuristic tool in writing process to think of and organize the ideas. Mc Quade claimed that metaphor could play a critical role throughout the entire process of composition (Ortony, 1993).

Therefore, it is advisable to cultivate the metaphoric awareness to help students become more and more conceptually competent in writing. Once the students' MC is established, students can develop and illustrate their thoughts from 


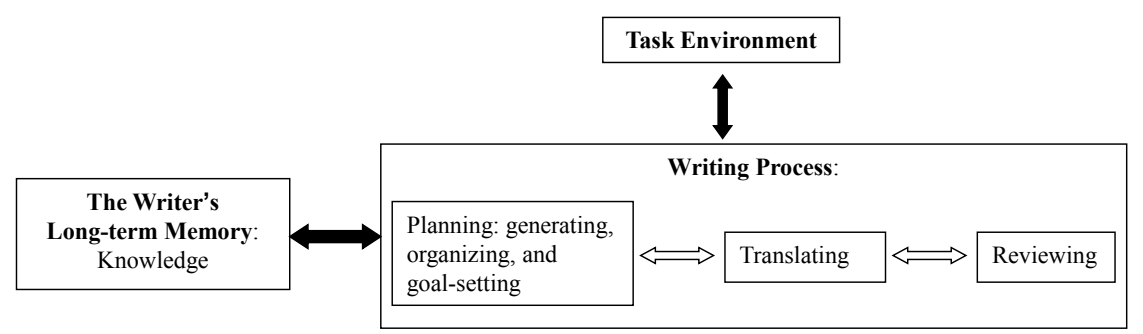

Figure 1. Cognitive process of writing.

different perspectives in the metaphorical network, and enrich the content. This article will explore the role of MC in college English writing.

The participants of this research consisted of 116 non-English freshmen, who accepted formal English learning under the same teaching system for over 7 years. They were divided into the experimental group (EG) and the controlled group (CG). Their average scores in the MET, before they were admitted in Tianjin Polytechnic University, were 102.7 and 100.3 respectively, showing no statistically significant difference. During one-year experimental teaching, EG subjects were given the instruction on metaphorical concepts, and trained to think in a metaphorical and systematic way to develop their MC, while CG subjects were taught in traditional way without the knowledge of metaphor.

The two groups were tested (t1) before they started their experimental learning, and given two final tests on the topic "On-line Shopping" (f1) and "City Life or Country Life" (f2) after one year. The topics were closely related to the daily life of college students, and very familiar to them. All subjects were asked to write short essays of 200 words about the given topics within 30 minutes.

The test papers were all evaluated referring to the scoring guide for CET (College English Test) by the English teachers from Tianjin Polytechnic University to avoid subjective bias. In terms of structure, logic and language in their test papers, full mark of 15, students' essays were divided into five ranks: 13 - 15, 10 12, $7-9,4-6$, and $1-3$. Then, teachers would work out lexical density (LD) in each essay, the percentage of metaphorical expressions (ME), and linguistic errors. All data collected were analyzed by means of the SPSS 13.0.

- Lexical words include nouns, lexical verbs, adjectives, adverbs.

$\mathrm{LD}=$ (number of lexical words/total number of words) $\times 100 \%$

- Percentage of $\mathrm{ME}=$ (number of metaphorical expressions/total number of sentences) $\times 100 \%$

- Percentage of the linguistic errors $=$ (number of wrong sentences/total number of sentences) $\times 100 \%$

The between-group comparison in their tests witnessed the significant difference on students' lexical density, metaphorical expressions, and linguistic errors, which are the contributing factors to writing score.

After one-year experimental teaching, EG subjects made evidently more progress in $\mathrm{LD}$, which is visibly higher in their texts as shown in Table 1, who did not perform well in searching for proper words to suit the context to achieve 
the fluency and appropriateness. The higher the lexical density is, the more lexical expressions they hire to elaborate their statements and enrich the contents in their texts. Chances are that with the training and practice on MC, EG subjects became active learners to use English in metaphorical mapping. It indicates that MC makes contribution to enriching words and expressions.

As shown in Table 2, EG group performs better in ME than CG does, who failed to produce multiple expressions to give detailed account of their main idea and thesis statements. During the one-year instruction and training, EG's MC was established. As a result in the metaphorical network, their thoughts could be developed and illustrated from different perspectives, which contributed to the diversity and coherence in their arguments. Lacking in metaphorical awareness, by contrast, CG tended to use the expressions of oral style, such as "I think ...", "we all know that ...", "you may think that ...", and "the reason is that ...", etc., Granger (1998: p. 155) called "active discourse frames", which conformed to the sentences of Chinese pattern in their texts.

Subjects in EG have higher lexical density, more metaphorical expressions, and less linguistic errors, which make contribution to rising score (see Table 3). It means that application of conceptual-metaphor theory has positive impact on EG's writing skills and their writing scores.

Table 1. Lexical density in the tests.

\begin{tabular}{cccc}
\hline & LDt 1 & LDf1 & LDf2 \\
\hline CG & $0.233 \pm 0.034$ & $0.286 \pm 0.0222$ & $0.293 \pm 0.0214$ \\
EG & $0.244 \pm 0.031$ & $0.384 \pm 0.019$ & $0.405 \pm 0.017$ \\
$\mathrm{t}$ & -1.814 & -25.442 & -31.155 \\
$p$ & 0.072 & 0.000 & 0.000
\end{tabular}

Table 2. Metaphorical expressions in the tests.

\begin{tabular}{cccc}
\hline & MEt1 & MEf1 & MEf2 \\
\hline CG & $0.138 \pm 0.027$ & $0.154 \pm 0.026$ & $0.249 \pm 0.025$ \\
EG & $0.142 \pm 0.029$ & $0.255 \pm 0.026$ & $0.544 \pm 0.041$ \\
$\mathrm{t}$ & -0.820 & -20.568 & -45.919 \\
$p$ & 0.414 & 0.000 & 0.000 \\
\hline
\end{tabular}

Table 3. Writing proficiency in tests.

\begin{tabular}{cccc}
\hline & $\mathrm{t} 1$ & $\mathrm{f} 1$ & $\mathrm{f} 2$ \\
\hline $\mathrm{CG}$ & $5.637 \pm 1.723$ & $6.379 \pm 1.399$ & $7.810 \pm 6.367$ \\
$\mathrm{EG}$ & $5.413 \pm 1.706$ & $8.879 \pm 1.23$ & $10.621 \pm 1.167$ \\
$\mathrm{t}$ & 0.703 & -10.220 & -3.306 \\
$p$ & 0.483 & 0.000 & 0.001 \\
\hline
\end{tabular}


Combined the theory of metaphor, MC helped EG effectively organize the structure to bring the topic into the discussions, and compose the multiple statements of supporting details and evidences in their texts. It is reasonable to say that MC is essential to improve writing proficiency.

\section{Conclusion}

The above results highlight the differences in lexical density, metaphorical expressions, and linguistic errors between the two groups' texts, and pinpoint the vital importance of $\mathrm{MC}$ in writing. To cultivate students' $\mathrm{MC}$ is virtually to encourage them to think in the target language and helps to develop students' creativity, which is neglected in the traditional teaching methods without metaphorical awareness. The hypothesis cannot be denied that cultivating MC can enhance English writing proficiency. Practically, the conceptual metaphor theory attempts to introduce a new approach to FLT.

\section{Acknowledgements}

This work was supported by "Research on Effect of Metaphorical Competence on students' Writing” from Tianjin Polytechnic University (No. 2010-3-39).

\section{Conflicts of Interest}

The author declares no conflicts of interest regarding the publication of this paper.

\section{References}

Danesi, M. (1986). The Role of Metaphor in Second Language Pedagogy. Rossegna Italiana di Linguisitica Applicata, 18, 1-10.

Dvorak, J. C. (1986). InfoWorld. New York: InfoWorld Media Group, Inc.

Granger, S. (1998). Prefabricated patterns in advanced EFL writing: collocations and formulae. Phraseology: Theory, Analysis and Applications. Oxford: Clarendon Press.

Knoeller, C. (2009). Driving Home at Midnight in a Dense: Using Metaphor to Explore Writing Processes. http://www.nwp.org/cs/public/print/resource/1790

Ortony, A. (1993). Metaphor and Thought. Cambridge: Cambridge University Press. https://doi.org/10.1017/CBO9781139173865

Raimes, A. (1983). Techniques in Teaching Writing. Oxford: Oxford University Press.

Ricoeur, P. (1978). The Rule of Metaphor: Multi-Disciplinary Studies in the Creation of Meaning in Language. Toronto: University of Toronto Press. 